\title{
Pentingnya Analisis Cluster Berbasis Spasial dalam Penanggulangan Tuberkulosis di Indonesia
}

\section{The Importance of Spatial-Based Cluster Analysis for Tuberculosis Control in Indonesia}

\author{
Dyah Wulan Sumekar Rengganis Wardani* Lutfan Lazuardi** Yodi Mahendradhata*** Hari Kusnanto**
}

\begin{abstract}
*Bagian Ilmu Kesehatan Masyarakat Fakultas Kedokteran Universitas Lampung, **Bagian Ilmu Kesehatan Masyarakat Fakultas Kedokteran Universitas Gadjah Mada, ***Pusat Kedokteran Tropis Fakultas Kedokteran Universitas Gadjah Mada
\end{abstract}

\begin{abstract}
Abstrak
Pengendalian tuberkulosis telah meningkatkan angka kesembuhan dan menyelamatkan banyak jiwa, tetapi kurang berhasil menurunkan insiden tuberkulosis. Oleh karena itu, pengendalian tuberkulosis menekankan pada kebijakan determinan sosial karena determinan sosial secara langsung dan melalui faktor risiko tuberkulosis berpengaruh terhadap tuberkulosis. Hasil telaah literatur menunjukkan bahwa stratifikasi determinan sosial menyebabkan clustering tuberkulosis, berupa pengelompokkan penderita tuberkulosis menurut lokasi geografis yang secara statistik signifikan. Pengetahuan tentang clustering sangat bermanfaat dalam pengendalian tuberkulosis, khususnya untuk menurunkan insiden tuberkulosis karena dapat memberikan informasi tentang lokasi populasi yang berisiko. Selain itu, telaah literatur menunjukkan bahwa implementasi analisis spasial memerlukan dukungan sumber daya yang tidak sedikit. Oleh karena itu, sebelum analisis cluster berbasis spasial dapat diterapkan, perlu didukung oleh penelitian yang menunjukkan kesiapan sumber daya dan efektivitas biaya.

Kata kunci: Determinan sosial, cluster, spasial, tuberkulosis
\end{abstract}

\footnotetext{
Abstract

Tuberculosis control has increased cure rate and saved million people, but has less success in reducing tuberculosis incidence. Therefore, tuberculosis control needs to put more emphasis on social determinants policy, since social determinants directly or through tuberculosis-risk factors affect tuberculosis. Literature reviews show that stratification of social determinants will cause tuberculosis clustering, a grouping of tuberculosis patients according geographical area that is statistically significant. Knowledge on the clustering is very useful to support tuberculosis-control program, especially for reducing tuberculosis incidence through highlighting the area of vulnerable population. On the other hand, literature reviews also show that implementation of spatial analysis requires adequate resources. Therefore, before tuberculosis cluster analysis can be implemented routinely, it should
}

be supported by researches that indicate resources readiness and cost effectiveness.

Keywords: Social determinants, cluster, spatial, tuberculosis

\section{Pendahuluan}

Sejak tahun 1947 hingga sekarang, World Health Organization (WHO) telah melakukan berbagai upaya pengendalian tuberkulosis (TB) paru, mulai dari pemanfaatan obat $\mathrm{TB}$, pengembangan program pelayanan dan manajemen untuk pengendalian TB hingga mengembangkan strategi Directly Observed Treatment Shortcourse (DOTS). Lebih jauh, sejak tahun 2000, WHO membentuk Stop TB Partnership untuk lebih meningkatkan pengendalian TB. Target yang harus dicapai oleh Stop TB Partnership yang berkaitan dengan Millenium Development Goals (MDG's) meliputi dua hal. Pertama, pada tahun 2015 tingkat prevalensi dan kematian TB menjadi setengah kali dibandingkan dengan tingkat prevalensi dan kematian pada tahun 1990. Kedua, pada tahun 2050 insiden kasus $<1$ juta populasi per tahun. ${ }^{1,2}$

Dengan pengendalian tersebut, angka kesembuhan TB mengalami peningkatan. Pada tahun 1995, angka kesembuhan berada pada kisaran 50\% naik hingga mencapai $88 \%$ pada tahun 2008 atau berkisar 36 juta jiwa. Selain itu, pengendalian TB juga telah menyelamatkan banyak jiwa. Lebih dari 6 juta jiwa penderita TB dapat diselamatkan pada tahun 1995 dan

Alamat Korespondensi: Dyah Wulan Sumekar Rengganis Wardani, Bagian Ilmu Kesehatan Masyarakat FK Universitas Lampung, Jl. S. Brojonegoro No. 1 Bandar Lampung 35145, Hp.08122516128, e-mail:dwwardani@yahoo.com 
2008. ${ }^{3}$ Namun, upaya pengendalian tersebut kurang berhasil menurunkan insiden kasus TB. Insiden kasus pada periode tahun 2004 - 2008, hanya mengalami penurunan sekitar $0,7 \%$ setiap tahun. ${ }^{3}$ Lebih jauh penurunan tersebut hanya terjadi di beberapa negara di Amerika dan Eropa, tetapi tidak di 13 negara dengan insiden TB tinggi seperti Sub Sahara Afrika dan Asia Tenggara. ${ }^{4}$ Data tahun 2012 menunjukkan bahwa secara global terdapat sekitar 8,6 juta insiden kasus TB, setara dengan 122 kasus per 100.000 populasi. Lima negara dengan insiden kasus terbesar tahun 2012 adalah India $(2,0-2,4$ juta), China $(0,9-1,1$ juta), Afrika Selatan (0,4 - 0,6 juta), Indonesia (0,4 0,6 juta), dan Pakistan (0,3 - 0,5 juta). Lebih jauh, insiden kasus di negara-negara tersebut pada tahun 2012 tidak mengalami penurunan dibanding insiden kasus pada tahun-tahun sebelumnya. ${ }^{5}$ Untuk menurunkan insiden TB, pengendalian TB akan "bergerak keluar dari kotak TB" dengan menekankan pada isu determinan sosial. ${ }^{6}$ Hal tersebut didasari pada kepentingan kebijakan dan intervensi determinan sosial untuk mendukung pengendalian TB. Selain itu, determinan sosial secara langsung atau melalui faktor risiko TB berpengaruh terhadap TB.3,7-9 Pentingnya determinan sosial dalam kesehatan juga dinyatakan oleh WHO dalam Rio Political Declaration on Social Determinant of Health pada tahun 2011.10

Determinan sosial merupakan terminologi yang merujuk pada pendidikan, pekerjaan, pendapatan, ras, dan kelas sosial yang menyebabkan terjadi stratifikasi atau diskriminasi dalam masyarakat. Keberadaan stratifikasi tersebut menyebabkan ketidakadilan kesehatan yang merupakan sebagian besar masalah kesehatan. ${ }^{11,12}$

Stratifikasi determinan sosial juga menyebabkan terjadi clustering atau pengelompokkan penderita TB. Hal tersebut disebabkan oleh penderita TB yang sebagian besar mempunyai determinan sosial rendah dan cenderung tinggal berkelompok dengan individu yang berasal dari determinan sosial rendah yang lain sehingga memperbesar risiko untuk terinfeksi TB. ${ }^{13}$ Pengetahuan tentang clustering TB tersebut sangat bermanfaat dalam penanggulangan TB karena memberikan informasi wilayah dengan risiko TB tinggi. Namun, hingga saat ini belum dilakukan penerapan analisis clustering dalam penanggulangan TB. Artikel ini bertujuan untuk melakukan telaah literatur pengaruh determinan sosial terhadap TB, khususnya clustering $\mathrm{TB}$, serta kesenjangan dalam penerapan analisis clustering TB serta rekomendasi peneliti-an yang berkaitan dengan penerapan analisis clustering TB dalam penanggulangan TB di Indonesia.

\section{Determinan Sosial}

Masalah kesehatan sebagian besar disebabkan oleh ketidakadilan kesehatan, yang merupakan kondisi ling- kungan tempat orang tersebut lahir, tumbuh, hidup, pekerjaan, dan usia. Kondisi-kondisi tersebut merujuk pada determinan sosial kesehatan, yang merupakan terminologi untuk menggabungkan kondisi sosial, ekonomi, politik, budaya, dan lingkungan, yang menyebabkan stratifikasi dalam masyarakat. Ada beberapa kondisi yang dapat menyebabkan stratifikasi dalam masyarakat, antara lain meliputi distribusi pendapatan; diskriminasi berdasarkan ras, gender, etnis, ketidakmampuan; serta struktur politik dan pemerintahan yang mendorong ketidakadilan ekonomi. ${ }^{11,12}$

Kejadian dan terpeliharanya stratifikasi tersebut di masyarakat memerlukan suatu mekanisme yang meliputi struktur pemerintahan, sistem pendidikan, struktur pasar, sistem keuangan, perhatian terhadap pembuatan kebijakan, provisi sosial serta proteksi sosial. Keberadaan mekanisme struktural tersebut menyebabkan perbedaan posisi sosial individu yang merupakan akar penyebab ketidakadilan kesehatan. Lebih jauh, perbedaan tersebut membentuk status kesehatan individu dan pendapatan melalui dampak determinan perantara, seperti kondisi lingkungan, keadaan psikososial, faktor perilaku dan biologi, dan pelayanan kesehatan itu sendiri. ${ }^{11,12}$ Diagram tentang determinan sosial yang menyebabkan stratifikasi di masyarakat (determinan struktural) dan determinan perantara kesehatan dapat dilihat pada Gambar 1.

Pada kasus TB, juga terdapat ketidaksamaan risiko dalam infeksi. Ketidaksamaan tersebut dapat dijelaskan dalam terminologi perbedaan status sosial ekonomi dan faktor struktural lain yang memengaruhi paparan risiko, kerentanan dan kemampuan untuk melindungi setelah sakit. Terdapat hubungan yang kuat antara insiden TB di negara-negara dengan Gross Domestic Product (GDP) per kapita. Juga terdapat hubungan kuat antara gradien sosial ekonomi dalam negara, pada semua tingkatan pendapatan, antarkota, dan antarrumah tangga dengan insiden TB. ${ }^{9}$ Lebih jauh, sebagian besar faktor risiko TB dihubungkan dengan kondisi sosial. Orang dari sosial ekonomi rendah cenderung tinggal di lingkungan yang padat, ketidakamanan pangan yang lebih besar, kurang pengetahuan tentang perilaku kesehatan, dan tidak ada akses terhadap kualitas pelayanan kesehatan dibandingkan kelompok dari sosial ekonomi tinggi. 3,14

\section{Analisis Spasial}

Analisis spasial adalah suatu inferensi visual terhadap peta yang merupakan gabungan dari data spasial dan data atribut. Data spasial merujuk pada suatu lokasi atau posisi di permukaan bumi, yang berupa koordinat, raster atau batasan administrasi wilayah. Sedangkan, data atribut merujuk pada karakteristik yang in situ, yang mencakup abiotik (semua unsur fisik lahan yang ada, yaitu tanah, geologi, iklim, dan air), biotik (flora dan fauna), 


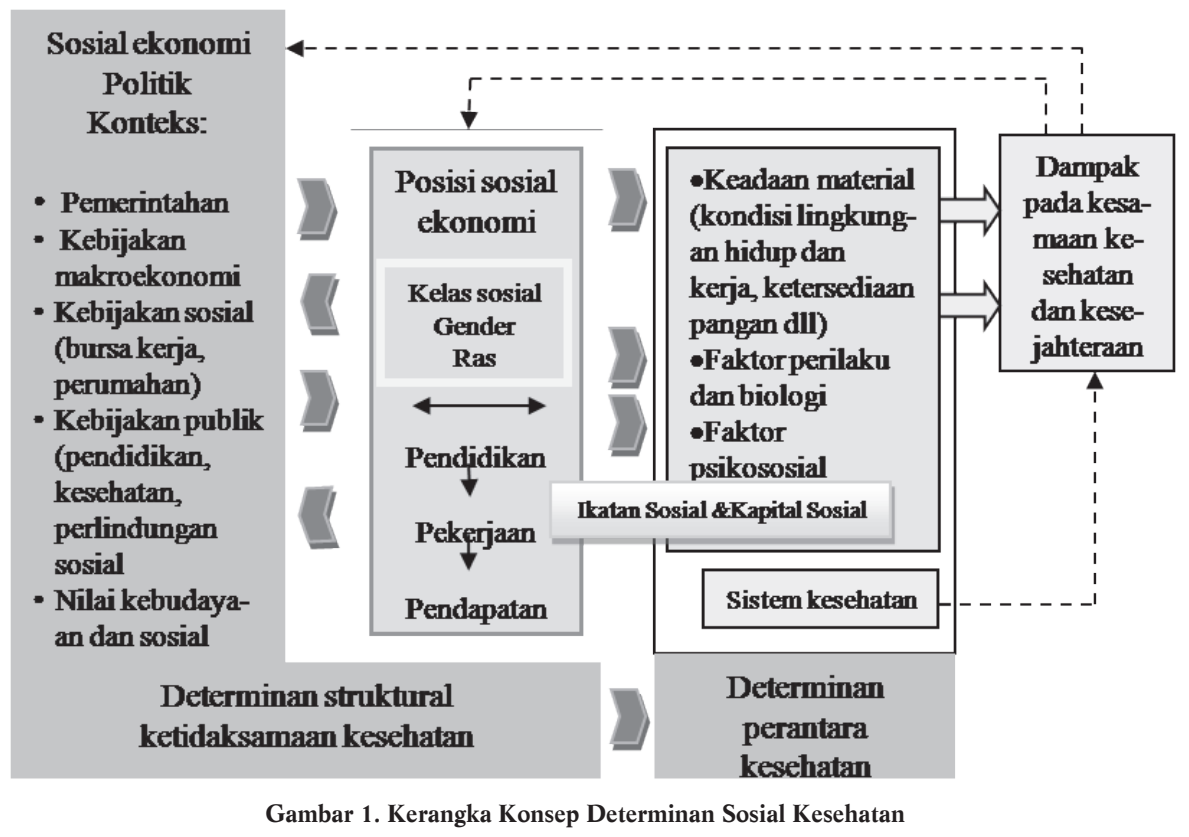

serta budaya (sosial ekonomi). Dengan analisis spasial, data spasial dan data atribut diolah menjadi informasi spasial, yang dapat digunakan sebagai alat bantu dalam perumusan kebijakan, pengambilan keputusan, dan/atau pelaksanaan kegiatan yang berhubungan dengan ruang kebumian. Dalam epidemiologi, analisis spasial sangat bermanfaat, terutama untuk mengevaluasi terjadinya perbedaan kejadian menurut area geografi dan mengidentifikasi clustering penyakit. ${ }^{15,16}$

\section{Cluster Tuberkulosis Berbasis Spasial}

Clustering merupakan pengelompokkan spasial atau space-time suatu penyakit yang signifikan secara statistik. Analisis clustering memiliki beberapa manfaat, yaitu menampilkan surveilance geographical suatu penyakit dan mengidentifikasi cluster penyakit secara spasial atau space-time serta mengetahui apakah cluster signifikan secara statistik; mengetahui apakah suatu penyakit terdistribusi secara random menurut tempat, menurut waktu serta menurut tempat dan waktu; mengevaluasi signifikansi statistik dari alarm cluster suatu penyakit; menampilkan prospektif real-time atau real-periodic dari surveilans penyakit untuk deteksi dini wabah. Cara kerja analisis clustering adalah dengan menempatkan jendela lingkaran pada peta studi sesuai dengan analisis dan model yang ditentukan. ${ }^{17}$

Terdapat beberapa analisis clustering, meliputi purely spatial, purely temporal, dan space-time. Pada purely spatial scan statistic jendela lingkaran akan ditempatkan berdasarkan hasil analisis menurut lokasi pada peta studi. Pada purely temporal scan statistic, jendela lingkaran akan ditempatkan berdasarkan hasil analisis menurut dimesi waktu. Sedangkan, pada space-time scan statistic, jendela lingkaran akan ditempatkan berdasarkan hasil analisis menurut lokasi yang juga dikorelasikan menurut dimensi waktu. ${ }^{17}$

Selain jenis analisis, juga terdapat beberapa model clustering, yaitu Poisson, Bernoulli, dan space-time permutation. Model Poisson digunakan apabila kasus bukanlah individu melainkan merupakan proporsional terhadap jumlah populasi yang merujuk pada personyears di suatu area geografis. Model Bernoulli digunakan untuk kasus merupakan individu yang terdiri dari kasus dan kontrol. Model ini membutuhkan koordinat geografis tiap kasus dan kontrol. Model space-time permutation hanya membutuhkan data kasus yang terdiri dari lokasi spasial dan waktu mulai sakit.

Analisis clustering diperoleh berdasarkan perbandingan jumlah kasus yang diobservasi pada cluster dibandingkan dengan jumlah kasus yang diharapkan bila lokasi spasial dan temporal saling bebas sehingga tidak ada interaksi space-time. Apabila dalam suatu kurun waktu jumlah kasus pada suatu area geografis tertentu dua kali lebih tinggi dibandingkan area geografis yang lain, maka pada area geografis tersebut terjadi cluster. ${ }^{17}$

Tuberkulosis merupakan penyakit yang memiliki kecenderungan untuk menyebabkan clustering. Hal tersebut disebabkan oleh penderita TB yang sebagian besar mempunyai determinan sosial rendah cenderung tinggal berkelompok dengan individu yang berasal dari determinan sosial rendah yang lain, yang memperbesar risiko untuk terinfeksi TB. Pengelompokkan tersebut me- 
mungkinkan terdapat perbedaan insiden kasus antarlokasi geografis. ${ }^{13}$

Beberapa peneliti mempelajari clustering kejadian TB. Penelitian di Distrik Almora, India, menunjukkan bahwa penderita TB di distrik tersebut membentuk tiga cluster. ${ }^{18}$ Penelitian di Beijing menunjukkan bahwa penderita TB membentuk dua cluster di daerah yang mayoritas berpenduduk migran dengan sosial determinan yang rendah. ${ }^{19}$ Penelitian di Hermosillo, Meksiko, mendapatkan penderita TB berkelompok di Hermosillo bagian utara, selatan dan timur, yang mempunyai determinan sosial rendah. ${ }^{20}$ Penelitian di Fukuoka, Jepang, menunjukkan bahwa penderita TB mengelompok di daerah tambang batu bara yang sebagian besar adalah migran dengan determinan sosial rendah. ${ }^{13}$ Penelitian di Portugal mendapatkan bahwa penderita TB mengelompok pada dua distrik dari enam distrik yang ada di kota tersebut. Kedua distrik tersebut mempunyai lebih banyak populasi imigran, penduduk yang tidak bekerja dan lingkungan yang padat. ${ }^{21}$ Penelitian di Vitoria, Brazil, juga menunjukkan bahwa terdapat clustering penderita TB di wilayah dengan determinan sosial rendah. ${ }^{22}$

\section{Kesenjangan Penerapan Analisis Cluster Tuberkulosis Berbasis Spasial dalam Penangulangan Tuberkulosis}

Informasi clustering TB yang dihasilkan pada penelitian di Portugal diharapkan dapat membantu mengembangkan intervensi TB yang efektif yang disertai dengan peningkatan pendidikan dan kampanye kebijakan sosial. ${ }^{21}$ Informasi clustering TB pada penelitian di Brazil diharapkan dapat membantu program pengendalian TB dalam mengalokasikan sumber daya pada populasi di daerah clustering TB yang merupakan populasi berisiko. ${ }^{22}$ Informasi clustering TB di Hermosillo, Mexico, diharapkan dapat menunjukkan populasi berisiko. ${ }^{20}$ Demikian pula clustering TB di Almora, India, Beijing, China, dan Fukuoka, Jepang, diharapkan juga dapat menunjukkan populasi yang berisiko berada, yang sangat bermanfaat bagi penanggulangan TB. 13,18,19 Walaupun analisis clustering TB sangat berpotensi menghasilkan informasi yang bermanfaat dalam penanggulangan $\mathrm{TB}$, tetapi belum terdapat bahasan penerapan analisis tersebut dalam penanggulangan TB. ${ }^{13,18-22}$

Beberapa faktor menjadi kendala penerapan analisis cluster berbasis spasial dalam penanggulangan TB. Studi kasus penerapan infrastruktur berbasis Sistem Informasi Geografis (SIG) di New Jersey menunjukkan bahwa untuk proses implementasi sistem tersebut membutuhkan dana, staf yang terlatih, perangkat lunak, perangkat keras, pelatihan yang kontinu serta partisipasi dari semua wilayah yang terkait. Proses implementasi tersebut juga membutuhkan waktu yang cukup lama, yaitu lima tahun. ${ }^{23}$ Lebih jauh, untuk dapat dilakukan analisis cluster berbasis spasial, juga diperlukan pengumpulan koordinat geografis penderita TB secara kontinu. Koordinat geografis merupakan salah satu representasi lokasi geografis, yang berupa garis lintang dan garis bujur. Untuk mendapatkan koordinat geografis suatu lokasi diperlukan suatu proses digitasi yang dapat dilakukan dengan alat bantu Geographical Positioning System (GPS). ${ }^{15}$ Koordinat geografis penderita TB merupakan data utama untuk dapat dilakukannya analisis clustering TB.

Di beberapa negara, koordinat geografis penderita TB telah dikumpulkan secara rutin. Di Hongkong, alamat penderita TB yang telah divalidasi dilakukan digitasi secara manual untuk mengetahui koordinat geografis. Proses tersebut dilakukan oleh District Council Constituency Area (DCCA) di bawah Departemen Kesehatan. ${ }^{24}$ Di Brazil, Portugal, dan China, walaupun data koordinat geografis penderita TB belum dikumpulkan secara rutin, telah terdapat studi kontinu atau sensus selama beberapa tahun. 19,21,22 Di Indonesia, kegiatan program penanggulangan $\mathrm{TB}$ belum mencakup pengumpulan data geografis penderita TB. ${ }^{25}$

\section{Penelitian untuk Mendukung Penerapan Analisis Cluster Berbasis Spasial}

Analisis cluster TB berbasis spasial sangat bermanfaat dalam penanggulangan TB. Di sisi lain, penerapan analisis tersebut harus didukung oleh kesiapan sumber daya yang tidak sedikit. Oleh karena itu, perlu dilakukan penelitian untuk menunjukkan bahwa analisis cluster TB berbasis spasial dapat dan layak untuk diterapkan. Penelitian tentang kesiapan perangkat lunak, perangkat keras, staf yang terlatih dan pelatihan yang kontinu perlu dilakukan untuk mengetahui kesiapan sumber daya. Penelitian tentang prediksi biaya yang dapat dihemat dan biaya yang harus dikeluarkan apabila melaksanakan analisis cluster TB berbasis spasial juga perlu dilakukan untuk mengetahui efektivitas biaya.

\section{Kesimpulan}

Clustering TB terjadi di wilayah dengan determinan sosial yang rendah, yang merupakan populasi berisiko tinggi terhadap TB. Pengetahuan tersebut sangat bermanfaat dalam penanggulangan $\mathrm{TB}$, terutama dalam menurunkan insiden $\mathrm{TB}$, karena memberikan petunjuk di mana populasi tersebut berada. Namun, penerapan analisis cluster berbasis spasial, seperti penerapan analisis spasial lain, memerlukan dukungan sumber daya yang tidak sedikit.

\section{Saran}

Implementasi analisis cluster sebagai upaya dalam penanggulangan TB di Indonesia perlu didukung oleh penelitian yang menunjukkan kesiapan sumber daya dan efektivitas biaya. 


\section{Daftar Pustaka}

1. Raviglione MC, Pio A. Evolution of WHO policies for tuberculosis control, 1948 - 2001. The Lancet. 2002; 359: 775-80.

2. World Health Organization. Stop TB Partnership WHO. The Stop TB Strategy. Building on and Enhancing DOTS to Meet the TB-Related Millennium Development Goals. Geneva: WHO; 2006.

3. Lönnroth K, Castro KG, Chakaya JM, Chauhan LS, Floyd K, Glaziou P, et al. Tuberculosis control and elimination 2010 - 50: cure, care, and social development. The Lancet. 2010; 375 (9728): 1814-29.

4. Dye C, Lönnroth K, Jaramillo E, Williams B, Raviglione M. Trends in tuberculosis incidence and their determinants in 134 countries. Bulletin World Health Organization. 2009; 87: 683-91.

5. WHO. Global tuberculosis report 2013. Geneva: WHO; 2013.

6. Raviglione. Tuberculosis prevention, care and control, 2010-2015: framing global and WHO strategic priorities. In Report of The Ninth Meeting 9-11 November 2009. Geneva: World Health Organization; 2009.

7. Lönnroth K, Holtz TH, Cobelens F, Chua J, Leth F Van, Tupasi T, et al Inclusion of information on risk factors, socio-economic status and health seeking in a tuberculosis prevalence survey. International Journal of Tuberculosis and Lung Disease. 2009; 13(2): 171-6.

8. Lönnroth K. Risk Factors and Social Determinants of TB. The Union NAR Meeting 24 Feb 2011 [online]. 2011 [cited 2012 Jul 12]. Available from: http://www.bc.lung.ca/association_and_services/documents /KnutUnionNARTBriskfactorsanddeterminantsFeb201.pdf

9. Rasanathan K, Sivasankara Kurup A, Jaramillo E, Lönnroth K. The social determinants of health: key to global tuberculosis control. International Journal of Tuberculosis and Lung Disease. 2011 Jun; 15(6):S30-6

10. WHO. Rio political declaration on social determinants of health. Rio de Janeiro: WHO; 2011

11. WHO. Closing the gap: policy into practice on social determinants of health. Geneva: WHO; 2011.

12. Solar O, Irwin A. A conceptual framework for action on the social determinants of health. Social Determinants of Health Discussion Paper 2 (Policy and Practice). Geneva: WHO; 2010.

13. Onozuka D, Hagihara A. Geographic prediction of tuberculosis clusters in Fukuoka, Japan, Using the space-time scan statistic. BMC Infectious Disease. 2007; 7(26).

14. Lönnroth K, Jaramillo E, Williams BG, Dye C, Raviglione MC. Drivers of tuberculosis epidemics: the role of risk factors and social determi- nants. Social Science and Medicine. 2009; 68: 2240-6.

15. Lai PC, So FM, Chan K. Spatial epidemiological approach in disease mapping and analysis. New York: CRC Press LLC; 2009.

16. Pemerintah Republik Indonesia. Undang-Undang Republik Indonesia Nomor 4 Tahun 2011 tentang Informasi Geospasial [online]. 2011[diakses tanggal 30 Oktober 2012]. Diunduh dalam: http://www.bakosurtanal.go.id.

17. Kulldorff M. SaTScan User Guide for Version 9.0 [manuscript on internet]. 2010 [cited 2013 Apr 13]. Available from: http://www. satscan.org/cgi_bin/satscan/register.pl/SatScan_Users_Guide.pdf?todo=process-userguide-download.

18. Tiwari N, Adhikari CMS, Tewari A, Kandpal V. Investigation of geospatial hotspots for the occurrence of tuberculosis in Almora District, India, using GIS and spatial scan statistic. International Journal of Health Geographics. 2006; 5(33).

19. Jia ZW, Jia X, Liu Y, Dye C, Chen F, Chen C, et al. Spatial analysis of tuberculosis cases in migrants and permanent residents, Beijing, 20002006. Emerging Infectious Disease. 2008; 14(9): 2000-6.

20. Alvarez-Hernández G, Lara-Valencia F, Reyes-Castro P, Rascón-Pacheco R. An analysis of spatial and socio-economic determinants of tuberculosis in Hermosillo, Mexico, 2000-2006. International Journal of Tuberculosis and Lung Disease. 2010 Jun; 14(6): 708-13.

21. Couceiro L, Santana P, Nunes C. Pulmonary tuberculosis and risk factors in Portugal: a spatial analysis. International Journal of Tuberculosis and Lung Disease. 2011; 15(11): 1445-54.

22. Maciel E, Pan W, Dietze R, L PR, Vinhas S, Ribeiro F, et al. Spatial patterns of pulmonary tuberculosis incidence and their relationship to socio-economic status in Vitoria, Brazil. International Journal of Tuberculosis and Lung Disease. 2010; 14(11): 1395-402.

23. Artigas F, Elefante D, Marti A, State T, Warren NJ, Hall S, et al. Geographic information sharing: a regional approach in Northern New Jersey, USA. Information Polity. 2009; 14: 127-39.

24. Pang PT-T, Leung CC, Lee SS. Neighbourhood Risk Factors for Tuberculosis in Hong Kong. International Journal of Tuberculosis and Lung Disease. 2010 May; 14(5): 585-92.

25. Kementrian Kesehatan Republik Indonesia Direktorat Jenderal Pengendalian Penyakit dan Penyehatan Lingkungan. Strategi Nasional Pengendalian TB di Indonesia 2010-2014. Jakarta: Kementrian Kesehatan Republik Indonesia Direktorat Jenderal Pengendalian Penyakit dan Penyehatan Lingkungan; 2011. 